
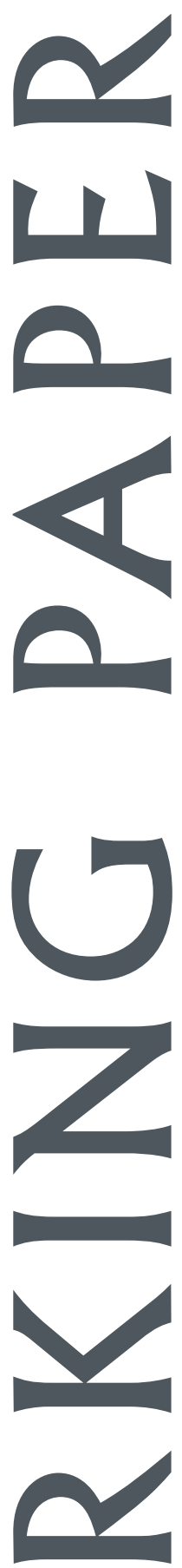

EAST-WEST CENTER 
The U.S. Congress established the East-West Center in 1960 to foster mutual understanding and cooperation among the governments and peoples of the Asia Pacific region including the United States. Funding for the Center comes from the U.S. government with additional support provided by private agencies, individuals, corporations, and Asian and Pacific governments.

East-West Center Working Papers are circulated for comment and to inform interested colleagues about work in progress at the Center.

For more information about the Center or to order publications, contact:

Publication Sales Office

East-West Center

1601 East-West Road

Honolulu, Hawaii 96848-1601

Telephone: 808-944-7145

Facsimile: 808-944-7376

Email: ewcbooks@EastWestCenter.org

Website: www.EastWestCenter.org 


\title{
Sex Differentials in Childhood Feeding, Health Care, and Nutritional Status in India
}

\author{
Vinod Mishra, T.K. Roy, and Robert D. Retherford
}

Vinod Mishra is a Fellow in Population and Health Studies at the East-West Center in Honolulu.

T.K. Roy is a Professor and the Director of the International Institute for Population Sciences in Mumbai.

Robert D. Retherford is a Senior Fellow and the Coordinator of Population and Health Studies at the East-West Center in Honolulu.

East-West Center Working Papers: Population and Health Series is an unreviewed and unedited prepublication series reporting on research in progress. The views expressed are those of the authors and not necessarily those of the Center. Please direct orders and requests to the East-West Center's Publication Sales Office. The price for Working Papers is $\$ 3.00$ each plus shipping/handling.

Address correspondence to: Dr. Vinod Mishra, Population and Health Studies, East-West Center, 1601 East-West Road, Honolulu, HI 96848-1601, USA; Tel: (1-808) 944-7452; Fax: (1-808) 944-7490; Email: MishraV@EastWestCenter.org. 


\section{Sex differentials in childhood feeding, health care, and nutritional status in India}

Vinod Mishra ${ }^{\dagger}$, East-West Center, Honolulu

T.K. Roy, International Institute for Population Sciences, Mumbai

Robert D. Retherford, East-West Center, Honolulu

Abstract: Strong preference for sons in South Asia is well documented, but evidence on female disadvantage in childhood feeding, health care, and nutritional status is inconclusive. This paper examines sex differentials in indicators of childhood feeding, health care, and nutritional status of children under age 3 by birth order and sex composition of older living siblings. Data are from India's 1992-93 and 1998-99

National Family Health Surveys. The analysis finds three reasons for inconclusive evidence on female disadvantage in aggregate analyses. First, discrimination against girls is limited to children of certain birth orders and sex compositions of older siblings, who constitute a relatively small fraction of all children. Second, discrimination against girls when boys are in short supply and discrimination against boys when girls are in short supply cancel each other to some extent. Third, some discrimination against girls (e.g., in exclusive breastfeeding at 6-9 months) is nutritionally beneficial to girls. Separate analyses for north and south India find that gender discrimination is as common in south India as in the north, where son preference is generally much stronger.

Key words: Gender, discrimination, feeding, health care, nutrition, children, India

\footnotetext{
${ }^{\dagger}$ Address for correspondence: East-West Center, 1601 East-West Road, Honolulu, HI 96848-1601; Phone: (808) 944-7452; Fax: (808) 944-7490, Email: MishraV@EastWestCenter.Org.

Authors thank Gayle Yamashita and Sally Dai for programming and research assistance. Authors also thank Fred Arnold and Minja Choe for valuable comments. An earlier version of this paper was presented at the 2003 Population Association of America annual meeting, Minneapolis, May 1-3, 2003.
} 


\section{INTRODUCTION}

A recent review of 306 child nutrition surveys from developing countries concluded that evidence on sex differentials in undernutrition does not support the notion that antifemale bias in intra-household food allocation and health care is causing excess female undernutrition (Marcoux 2002). The author noted, "the statistical evidence tells us that, where detectable differences by sex exist, boys usually fare worse than girls by anthropometric indicators." Sommerfelt and Arnold (1998) reached a similar conclusion after reviewing evidence on sex differentials in stunting, underweight, and wasting from 41 Demographic and Health Surveys. Sommerfelt and Piani (1997) examined sex differences in immunization coverage in 28 countries that participated in Demographic and Health Surveys during 1990-1994 and found a "slight tendency for vaccination coverage to be somewhat higher among girls than among boys." A detailed review of literature on intra-household distribution of food found little evidence of discrimination against girls in feeding (Haddad et al. 1996). In an individual case study, Basu (1993), drawing on field data from India and a review of literature on household allocation of food in South Asia, where anti-female discrimination is believed to be widespread, found no evidence that girls are discriminated against in feeding. Mishra et al. (1999) analyzed data from a large national survey in India and found that boys and girls were about equally likely to be stunted and underweight but boys were slightly more likely than girls to be wasted. Schoenbaum et al. (1995) also found no consistent evidence of gender differences in feeding or nutritional status among children age $0-18$ months in the Gaza Strip. 
This overwhelming evidence of a lack of sex differentials in childhood feeding and nutritional status flies in the face of considerable evidence of strong son preference in many parts of South and East Asia, the Middle East, and North Africa (Arnold 2001). In much of South Asia, sons are preferred over daughters for a number of economic, social, and religious reasons, including financial support, old-age security, property inheritance, dowry, family lineage, prestige and power, birth and death rituals, and beliefs about religious duties and salvation (Arnold et al. 2002; Arnold et al. 1998; Arnold 1992; Kishor 1993; Das Gupta 1987; Das Gupta and Mari Bhat 1997; Basu 1989; Chen et al. 1981; Levine 1987; Miller 1981; Niraula and Morgan 1995; Stash 1996; Abeykoon 1995; Das 1987; Karki 1988; Caldwell and Caldwell 1990; Bardhan 1988; Dyson and Moore 1983). Strong preference for sons often manifests itself in the form of discrimination against daughters (Arnold et al. 1998). It is believed to be responsible for many discriminatory practices against girls in feeding, health care, and education (Timaeus et al. 1998; Chen et al. 1981; Muhuri and Preston 1991; Govindaswamy and Ramesh 1997; Caldwell and Caldwell 1990; Ganatra and Hirve 1994; Koenig and D’Souza 1987; Bairagi 1986; Basu 1989; Sen and Sengupta 1983; Ravindaran and Mishra 2000; Nag 1991; Riley 1997; Behrman 1998) and ultimately for excess female child mortality rates (Arnold et al. 1998; Choe et al. 1998; Das Gupta 1987; Hill and Upchurch 1995; Kishor 1995; Arnold 1992; Pebley and Amin 1991; Visaria 1987; Elfindri 1993; Bairagi 1986; Tabutin and Willems 1995; Dyson and Moore 1983; Murthi et al. 1995; Makinson 1994; Pelletier 1998). Son preference has been associated with preferential abortion of female fetuses and even to female infanticide (Arnold et al. 2002; Goodkind 1996; Sudha and Rajan 1999). Two recent studies in India have linked son preference to high sex ratios at 
birth, which indicate sex-selective abortion (Arnold et al. 2002; Retherford and Roy 2003). Strong son preference is also believed to be partly responsible for high male/female (M/F) population sex ratios in India (Visaria and Visaria 1995).

What can we conclude from this conflicting evidence on the effects of son preferenceexcess female child mortality and sex-selective abortion, on the one hand, and overwhelming evidence of a lack of sex differentials in intra-household feeding practices and measures of nutritional status, on the other? Can we conclude that the case for gender discrimination in feeding and health care against girls has been overstated and that in reality there is little or no discrimination? If so, how can we explain excess female child mortality and the widespread and rising prevalence of sex-selective abortion?

In this paper, we present evidence that discrimination against girls is not across the board and that it depends to a considerable extent on the birth order of the index child and the sex composition of older living siblings, which we measure as mother's number of living sons at each birth order. This argument is consistent with previous research in South Asia that has shown that mortality tends to be higher among girls in families with a larger number of older female siblings (Arnold et al. 1998; Choe et al. 1998; Muhuri and Preston 1991; Amin 1990; Das Gupta 1987). This latter finding is perhaps not surprising, because there is evidence that, despite an overall preference for sons, most couples also desire to have at least one daughter (Arnold 2001; Niraula and Morgan 1995; Bairagi and Langsten 1986; Muhuri and Preston 1991; Dharmalingam 1996). Indeed, in India, the proportion of ever-married women age 15-49 who want at least one daughter ( 80 
percent) is almost as large as the proportion who want at least one son ( 85 percent). Even in the north Indian state of Uttar Pradesh, where son preference is very strong, 89 percent of women want at least one daughter. These statistics suggest that discrimination against daughters in feeding, treatment, and care is likely to depend in part on the number and sex composition of living children that a couple already has. For example, a couple whose first two children are both daughters may be more likely to neglect the third child if it is a daughter than if it is a son, but a couple whose first two children are both sons may be more likely to neglect the third child if it is a son than if it is a daughter.

It is also the case that not all discrimination is necessarily harmful to girls. For example, in populations with strong son preference, boys are typically more likely than girls to be exclusively breastfed at 6-9 months of age, when breastfeeding alone is considered inadequate to meet the energy and nutrient needs of infants (WHO 2001; Anandaiah and Choe 2000; Gibson et al. 1998; Gopalan and Puri 1992). Also, in populations with strong son preference, boys are typically more likely than girls to be carried or kept in the kitchen area while cooking, thereby inadvertently exposing boys to higher levels of health-damaging air pollution (Mishra et al. 2002).

Our analysis of gender discrimination ${ }^{1}$ is based on data from India's first and second National Family Health Surveys, conducted in 1992-93 (NFHS-1) and 1998-99 (NFHS2). Each survey collected information on a number of indicators of feeding, health care, and nutritional status for children born in the three years preceding the survey. These included whether the child received adequate breastfeeding, whether the child receives 
milk and solid or mushy foods on a regular and timely basis, whether the child is fully immunized, and whether advice or treatment was sought when the child was sick with an acute respiratory infection (ARI) or diarrhea in the preceding two weeks. The surveys also collected data on height and weight of children under age 3 and on ever-married women age 15-49. NFHS-2 (but not NHFS-1) additionally collected data on whether the child receives fruits and green, leafy vegetables on a regular basis and on blood hemoglobin levels of children and their mothers. Both surveys also collected data on a range of demographic, socioeconomic, and health characteristics of mothers of these children and their households.

The analytical approach for detecting the effects of gender discrimination is to assess, among children of specified birth order, the effects of index child's sex and mother's number of living sons (among her earlier children) on selected indicators of child feeding practices, health care, and nutritional status while controlling for a number of demographic and socioeconomic variables that might otherwise confound the relationship. The basic hypotheses to be tested include the following: (1) If all or most previous children are daughters, there will be a tendency to treat a male child better than a female child. (2) If all or most previous children are sons, there will be a tendency to treat a female child better than a male child. (3) The first tendency will be greater than the second tendency, because, overall, preference for sons is stronger than preference for daughters. (4) The effects of child's sex and mother's number of living sons on feeding, health care, and nutritional status will be greater in north India than in south India, 
because son preference is stronger in north India (Dyson and Moore 1983; Clark 2000;

Arnold et al. 2002).

In addition, we hypothesize (5) that gender discrimination is less likely to occur in utilization of health services that are freely available (for example, childhood vaccinations), compared with those for which parents need to pay (for example, treatment-seeking for ARI and diarrhea). Similarly, (6) gender discrimination is less likely for foods that are less valued (both perceived value and monetary value), even if they are nutritionally beneficial. We also hypothesize that gender discrimination for a given feeding or health care indicator will depend on the overall prevalence of that indicator in the population. In other words, we expect a "transition effect" in gender discrimination, whereby discrimination is less common at low and high prevalence and more common in between. For example, we hypothesize (7) that gender discrimination in immunization coverage is less likely to occur in south India, where overall immunization levels are approaching universal coverage, than in the north, where the coverage is much lower. We also expect some "substitution effect" in gender discrimination, to the extent that couples in India are practicing sex-selective abortion. As described by Goodkind (1996), gender discrimination in feeding and care may be absent in families that use sexselective abortion as a tool to attain a desired sex composition of children, so that each child is wanted, regardless of its sex. In India as a whole, however, the prevalence of sexselective abortion is low, so that this "substitution effect" probably has little influence on our results. 


\section{DATA AND METHODS}

As already mentioned, data for this study are from India's first and second National Family Health Surveys (NFHS-1 and NFHS-2), conducted in 1992-93 and 1998-99, respectively. NFHS-1 collected data from a nationally representative sample (except Sikkim, the Kashmir region of Jammu and Kashmir state, and the small Union territories, which were not included) of 89,777 ever-married women age $13-49$, residing in 88,562 households. NFHS-2 collected data from a nationally representative sample (except the small Union Territories) of 90,303 ever-married women age 15-49, residing in 92,486 households. After incorporation of state-level or national-level sample weights, as appropriate, data from both surveys are representative at both the state and national levels. The analysis here is based on births during the three-year period before each survey to ever-married women age 15-49.

In both NFHS-1 and NFHS-2, the sample design was such that in some states certain categories of respondents (for example, those from urban areas) are oversampled, so that weights are needed to restore the correct proportions. State-level weights are designed to preserve the total numbers of households and ever-married women interviewed in each state, so that the weighted state total equals the unweighted state total. National-level weights are used when generating results at the national level, in which case the weighted national total equals the unweighted national total. Details of sample design are provided in the basic national survey reports for the two surveys (IIPS 1995; IIPS and ORC Macro 2000). 
Each survey collected data on a host of demographic, socioeconomic, and health indicators for selected households and for all ever-married women (age 13-49 in NFHS-1 and age 15-49 in NFHS-2) and their young children (under age 4 in NFHS-1 and under age 3 in NFHS-2 $)^{2}$. The analysis in this paper is restricted to ever-married women age 15-49 and their births in the three years preceding each survey.

For each child born during the reference period, the mother was asked a series of questions about breastfeeding, supplementary feeding, immunizations, and treatmentseeking for common childhood diseases such as acute respiratory infections (ARI) and diarrhea. To assess the physical growth and nutritional status of children, measurements of weight and height/length and blood hemoglobin levels were also obtained. Details about these measurements are included in the basic survey reports (IIPS 1995; IIPS and ORC Macro 2000).

From these data, we created 11 outcome variables pertaining to feeding, health care, and nutritional status of children under age 3. The three groups of outcome variables are:

\section{Variables relating to feeding:}

Received solid/mushy food ${ }^{3}$ during the last 24 hours (age 6-9 months)

Received breastfeeding for 24 months or longer (age 24-35 months)

Receives green, leafy vegetables or fruits daily ${ }^{4}$ (age 12-35 months)

Receives milk ${ }^{5}$ daily (age $24-35$ months) 


\section{Variables relating to health care:}

Fully immunized ${ }^{6}$ (age $12-23$ months)

Advice or treatment sought when sick with $\mathrm{ARI}^{7}$ during the two weeks before the survey Advice or treatment sought when sick with diarrhea during the two weeks before the survey

\section{Variables relating to nutritional status: ${ }^{8}$}

Stunting

Underweight

Wasting

Anemia $^{9}$

The analysis was carried out using both descriptive and multivariate statistical methods. Each outcome variable is binary (yes or no), so that logistic regression is an appropriate method of multivariate analysis. Units of analysis are births that occurred during the 3year period immediately preceding the survey. Analysis is restricted to the most recent birth occurring within the 3-year reference period in cases where more than one birth occurred during the period, so that each mother gets counted only once, thereby avoiding an additional source of clustering in the sample. Attention is also restricted to cases where no child (either the index child or a previous child) died between the birth of the index child and the time of the survey. 
For each of the 11 outcome variables, four logistic regressions are run, one for each birth order 1,2,3, and 4+. First this is done separately for each survey and for the pooled NFHS-1 and NFHS-2 samples for the whole country, then for a group of four northern states (Bihar, Madhya Pradesh, Rajasthan, and Uttar Pradesh) and a group of four southern states (Andhra Pradesh, Karnataka, Kerala, and Tamil Nadu), which for simplicity we shall usually refer to as "the north" and "the south." In the case of these two groups of states, the analysis is done only for the pooled NFHS-1 and NFHS-2 samples in order to increase the number of cases. The two variables not available from NFHS-1 - green, leafy vegetables or fruits daily and anemia — are not included in the analysis for north and south.

In the case of birth order 1, the principal predictor variable in the logistic regression is simply the sex of the index child, defined as a binary variable that equals 1 if male (ICM) and 0 if female (ICF).

In the case of birth order 2, the specification of the principal predictor variable takes into account interaction between index child's sex and mother's number of living sons. (By interaction is meant that the effect of index child's sex on a particular outcome variable differs according to the mother's number of living sons among her previous children.) Our principal predictor variable is therefore a composite variable that cross-classifies index child's sex and mother's number of living sons. The various categories of this composite variable are defined by the following dummy variables (each dummy variable 
takes the value of 1 if the child has the specified characteristics and the value of 0 if it does not):

S0ICM: $\quad$ Number of living sons is 0 , index child is male

S0ICF: Number of living sons is 0 , index child is female

S1ICM: $\quad$ Number of living sons is 1, index child is male

S1ICF: Number of living sons is 1, index child is female

In the case of no living sons, we treat "number of living sons 0 , index child female" as the reference category, so that the dummy variable SOICF is dropped from the regression equation. The coefficient of S0ICM then captures the effect of index child's sex. The same logistic regression equation is then re-run with S1ICF as the reference category in order to make the appropriate comparison of male and female children when mother's number of living sons is 1 .

In the case of birth order 3 , the categories of the composite variable are:

S0ICM: $\quad$ Number of living sons is 0 , index child is male

S0ICF: Number of living sons is 0 , index child is female

S1ICM: $\quad$ Number of living sons is 1, index child is male

S1ICF: Number of living sons is 1, index child is female

S2ICM: $\quad$ Number of living sons is 2, index child is male

S2ICF: Number of living sons is 2, index child is female 
and in the case of birth order $4+$ (treated as a group), the categories of the composite variable are:

S0ICM: $\quad$ Number of living sons is 0 , index child is male

S0ICF: $\quad$ Number of living sons is 0 , index child is female

S1ICM: $\quad$ Number of living sons is 1 , index child is male

S1ICF: $\quad$ Number of living sons is 1 , index child is female

S2+ICM: $\quad$ Number of living sons is $2+$, index child is male

S2+ICF: $\quad$ Number of living sons is $2+$, index child is female

The logic of the procedure for estimating the effect of index child's sex on a particular outcome variable is the same at birth orders 3 and $4+$ as at birth order 2: At each specified number $x$ of living sons, the logistic regression for the specified birth order is run without the variable SxICF, so that "number of living sons $x$, index child female" becomes the reference category. The coefficient of the dummy variable SxICM then captures the effect of index child's sex. This means that, in the case of birth order 3, the same logistic regression is run three times (corresponding to 0,1 , and 2 living sons among the mother's previous children), each time with a different reference category for the composite variable. In the case of birth order $4+$, the same logistic regression is also run three times (corresponding to 0,1 , and $2+$ living sons among the mother's previous children), each time with a different reference category for the composite variable.

The set of predictor variables in the logistic regressions includes not only the composite variable — index child's sex cross-classified by mother's number of living sons - but also 
a set of control variables. At first blush, it might appear unnecessary to include control variables, because if the sex of the index child is a random event, the index child's sex is not correlated with the control variables, which then may be left out of the logistic regression equation without biasing the coefficients of the dummy variables representing the composite variable. In India, however, index child's sex is not a random event, because of the non-negligible incidence of sex-selective abortion (Arnold et al. 2002; Retherford and Roy 2003). Because sex-selective abortion is correlated with socioeconomic status as well as some other variables, socioeconomic status and these other variables tend also to be correlated with the sex of the index child and must therefore be held constant by including them as additional control variables in the logistic regression equations. This is especially necessary when estimating the effect of index child's sex on the outcome variables when the mother's previous children are either all sons or all daughters, because in these cases the prevalence of sex-selective abortion is especially high (Retherford and Roy 2003).

The control variables included in the logistic regressions are: child's age $(0-5,6-12$, $12-23,24-35$ months), previous birth interval ( $<24$ months, $\geq 24$ months - variable omitted in the case of the logistic regressions for birth order 1), mother's age at the time of the birth of the index child $(<20,20-34,35+$ years), mother's pregnancy status (not pregnant, first trimester, second trimester, third trimester), mother's body mass index ${ }^{10}$ (underweight, normal, overweight or obese), mother's anemia level ${ }^{11}$ (normal, mild anemia, moderate or severe anemia), mother's education ${ }^{12}$ (illiterate, literate but less than middle school complete, middle school complete but less than high school complete, high 
school complete or higher), residence (urban, rural), religion (Hindu, Muslim, other ${ }^{13}$ ), caste/tribe $^{14}$ (scheduled caste, scheduled tribe, other backward caste, other), standard of living ${ }^{15}$ (low, medium, high), and geographic region ${ }^{16}$ (north, west, central, east, northeast, south $)^{17}$.

It is possible that at least some of these control variables interact with index child's sex, inasmuch as the effect of index child's sex on a particular outcome variable may vary by category of a control variable. But since the reason for including the control variables is simply to hold them constant, we have not specified any interactions between child's sex and the control variables.

\section{RESULTS}

In the presentation of results, we first discuss characteristics of children from NFHS-1 and NFHS-2. Next, we discuss overall sex differentials in the 11 outcome variables in the two surveys for all India and for the four northern and four southern states. We then present $\mathrm{M} / \mathrm{F}$ odds ratios as measures of causal effect of sex of index child on each of the 11 outcome variables, by birth order and sex composition of previous living children after controlling for the background variables. In the case of all India, M/F odds ratios are presented separately for NFHS- 1 and NFHS-2 as well as for the pooled NFHS-1 and NFHS-2 samples. In the case of the northern and southern states, M/F odds ratio are presented separately for the two groups of states, but only for the pooled NFHS-1 and NFHS-2 samples, since numbers of cases in some categories are often too small in each survey separately. In the analysis of the pooled sample, an additional control variable for 
survey ( 1 if NFHS-2, 0 if NFHS-1) is included in the logistic regression equations.

Effects of the control variables are not shown. The estimation of significance levels takes into account design effects due to clustering at the level of the primary sampling unit (rural village or urban block). The analysis was carried out using both SAS and STATA statistical software (SAS Institute, Inc. 2001; STATA Corporation, 2002).

\section{Characteristics of children included in the study}

Table 1 shows, for each survey, how the sample of children is distributed among categories of each of the predictor variables included in the analysis. In each survey, at each birth order in families with no previous living sons, there are more male children than female children in the sample. This is due not only to the biological sex ratio at birth (about 105 male births per 100 female births) but also to sex-selective abortion and unreported sex-selective infanticide. Given high preference for sons over daughters, mothers in India are more likely to stop childbearing when they get a son than when they get a daughter. This is particularly the case for third-order births when many women decide whether to stop or go on to have another child. In Table 1, the category of third birth and no living sons is considerably greater than the category of third birth with two living sons for each survey.

$<$ Table 1 about here $>$

The table also shows that about two-fifths of the children were infants and only about one-quarter were age 24-35 months in each survey, reflecting in large part the effect of infant and child mortality. Twenty-two percent of children were born within two years of a previous live birth, and about the same proportion were born to teenage mothers in each 
survey. Only 6 percent of children in NFHS- 1 and 4 percent in NFHS- 2 were born to mothers age 35 or older. In each survey, mothers of about 10 percent of the children born in the past 3 years were pregnant at the time of the survey. As mentioned earlier, data on mother's BMI and anemia were collected only in the second survey. Mothers of about two-fifths of children were underweight $\left(\mathrm{BMI}<18.5 \mathrm{~kg} / \mathrm{m}^{2}\right)$ and mothers of about 5 percent were overweight or obese $\left(\mathrm{BMI} \geq 25.0 \mathrm{~kg} / \mathrm{m}^{2}\right)$ at the time of the survey. More than half of the mothers (55 percent) were anemic, and mothers of one in five children (19 percent) were moderately to severely anemic at the time of the survey. The proportion of children with illiterate mothers declined from 66 percent in NFHS-1 to 59 percent in NFHS-2, and the proportion of children with mothers with at least a high-school education increased from 11 to 15 percent between the two surveys. ${ }^{18}$

About four-fifths of children live in rural areas. About four-fifths of children belong to Hindu households, about one-sixth to Muslim households, and the remaining 5 percent to households with some other religion. Twenty percent are from scheduled-caste households in NFHS-2, up from 13 percent in NFHS-1. The increase in the proportion of children belonging to scheduled-caste households is primarily due to differences in the way the questions on caste/tribe status of the household head were asked in the two surveys. ${ }^{19}$

In each survey, about two-fifths of children belong to households with a low standard of living and less than one-fifth belong to households with a high standard of living. Because of differences in the way the standard of living index was constructed in the two 
surveys, the proportions of children in the three living-standard categories are not precisely comparable between the two surveys. By geographic region, about one-half (47 percent) of children are from the central region, and about one-fifth (19 percent) are from the south region.

\section{Sex differentials in the outcome variables}

Before proceeding to the results of the multivariate analysis, we present overall raw values of sex differentials in the outcome variables, regardless of child's birth order, mother's number of living sons, and other characteristics of the child or its mother.

Childhood feeding. For all India, the proportion of 6-9-month-old children who received solid or mushy foods during the past 24 hours does not vary much by sex of child (Table 2). By region, however, the proportion of children receiving solid or mushy foods in the past 24 hours is much greater in the south than in the north. In NFHS-2, for example, 62 percent of boys and 60 percent of girls in the south received solid or mushy foods, compared with 19 percent of boys and 22 percent of girls in the north. In the north, girls are slightly more likely than boys to have received solid or mushy foods, but in the south the proportion receiving solid or mushy foods is about the same for boys and girls.

$<$ Table 2 about here $>$

Among children age 24-35 months, boys are slightly more likely than girls to be breastfed for 24 months or longer in both surveys. The overall prevalence of breastfeeding for 24 months or longer is much higher in the north than in the south. In NFHS-2, for example, 81 percent of boys and 78 percent of girls in the north received 
breastfeeding for 24 months or longer, compared with 52 percent of boys and 48 percent of girls in the south. Again regional differences are much larger than sex differences.

In India as a whole in NFHS-2, about three in ten children age 12-35 months receive green, leafy vegetables or fruits on a daily basis. Proportions receiving green, leafy vegetables or fruits on a daily basis are about the same in north and south. Boys and girls are about equally likely to receive green, leafy vegetables or fruits daily in the two regions and in India as a whole.

Among children age 24-35 months, boys are somewhat more likely to receive milk (other than breast milk or powdered milk) daily than girls. In NFHS-2, for example, the proportions receiving milk daily were 47 percent for boys and 43 percent for girls. In NFHS-1, these proportions were greater in the north than in the south, but in NFHS-2 there was no regional differential. The reasons for the disappearance of the regional differential are not clear but may have to do with differences in the way the question was asked in the two surveys. ${ }^{20}$

Immunization and health care. Among children age 12-23 months, boys are slightly more likely than girls to be fully immunized in both NFHS-1 and NFHS-2, and the proportions of boys and girls who are fully immunized increased somewhat between the two surveys in India as a whole. Proportions fully immunized are much higher in the south than in the north. In NFHS-2, for example, 66 percent of boys and 65 percent of girls age 12-23 months were fully immunized in the south, compared with 19 percent of 
boys and 15 percent of girls in the north. Between the two surveys, the proportions fully immunized increased in the south but declined slightly in the north. The male advantage in proportion fully immunized is very small in the south but slightly larger in the north.

Table 2 also shows sex differentials in the proportion of children for whom medical advice or treatment was sought when sick with an acute respiratory infection in the two weeks preceding the survey. In NFHS-1, about three-quarters of these children received advice or treatment for ARI, but this proportion declined somewhat in NFHS-2 in India as a whole. Boys were more likely than girls to have received advice or treatment in both surveys, both for all India and for north and south separately. The likelihood of seeking treatment for ARI was about the same in north and south in NFHS-1, but between the two surveys the proportions receiving treatment fell in the north but not in the south (except slightly for girls), so that in NFHS-2 the likelihood of treatment was considerably higher in the south than in the north.

In NFHS-1, boys were more likely than girls to have received medical advice or treatment for diarrhea during the two weeks preceding each survey, both for all India and for north and south separately. In NFHS-2, this sex differential in treatment-seeking is observed in the south but not in the north. In India as a whole in NFHS-2, boys were only slightly more likely (72 percent) than girls (70 percent) to receive advice or treatment when sick with diarrhea. The proportion of children receiving advice or treatment for diarrhea declined in the north for boys (but not for girls) and increased in the south for both boys and girls between the two surveys. 
Nutritional status. Boys and girls under age 3 were about equally likely to be stunted in both NFHS-1 and NFHS-2. Proportions stunted were considerably higher in the north than in the south in both surveys. In each survey, about one-half of boys and girls were stunted in the north, compared with about one-third of boys and girls in the south. Sex differentials in proportion underweight are similar to sex differentials in proportion stunted. Boys were more likely to be wasted than girls in NFHS-1 in all India and in the north, but boys and girls were about equally likely to be wasted in the south in NFHS-1 and in both all India and north and south separately in NFHS-2. Anemia levels were slightly higher among boys than among girls in NFHS-2, but the sex differentials are very small. Anemia among children was more prevalent in the north than in the south.

\section{Multivariate analysis}

Table 3 presents sex differentials in the selected indicators of childhood feeding, health care, and nutritional status by the index child's birth order and the sex composition of older living siblings. Results are based on logistic regression, and sex differentials are measured by $\mathrm{M} / \mathrm{F}$ odds ratios after controlling for the set of background variables shown earlier in Table 1. A M/F odds ratio for a given birth order and sex composition of older living siblings indicates the odds of a particular outcome when the index child is a boy, relative to the odds of that outcome when the index child is a girl. An odds ratio of 1.00 indicates that the odds of that outcome are the same for boys and girls.

$<$ Table 3 about here $>$ 
Childhood feeding. Table 3 shows that, in NFHS-2 among third-order births, boys were less likely than girls to receive solid or mushy foods during the last 24 hours in families with no living sons, but more likely than girls to receive solid or mushy foods in families with two living sons (no living daughters). Alternatively stated, boys age 6-9 months were more likely than girls to be exclusively breastfed in families with no living sons, but less likely than girls to be exclusively breastfed in families with no living daughters. This pattern of sex differentials is not observed at birth order 3 in NFHS-1, however, nor is it observed at other birth orders and sex compositions in either survey.

The sex differentials in the odds of breastfeeding for 24 months or longer also do not show any clear pattern by child's birth order and mother's number of living sons. There is also no clear pattern of sex differentials in the proportion of children age 12-35 months receiving green, leafy vegetables or fruits on a daily basis by child's birth order and mother's number of living sons, or in the proportion of children receiving milk (other than breast milk or powdered milk) daily by child's birth order and mother's number of living sons.

Immunization and health care. The clearest evidence of gender discrimination in full immunization is for third-order births in NFHS-2. Boys age 12-23 months born to mothers with no living sons are more than twice as likely to be fully immunized as girls in such families ( $\mathrm{OR}=2.14, p<0.01)$, while boys born to mothers with two living sons are less likely to be fully immunized than girls ( $\mathrm{OR}=0.74 ;$ n.s. $)$. With some exceptions, a similar pattern (M/F odds ratios declining as mother's number of living sons increases) is 
found at birth orders 2 and 4+ in both NFHS-1 and NFHS-2, although most of the odds ratios are not statistically significant. At birth order 3 in NFHS-1, however, this pattern is absent. Overall, there is some evidence of gender discrimination in full immunization, more so in NFHS-2 than in NFHS-1. By way of comparison, Pande (2003), using a different methodology and focusing only on rural persons in NFHS-1, found a significant effect of older-sibling sex composition on childhood immunization.

Evidence of gender discrimination is much stronger in the case of treatment-seeking for ARI. At each birth order, boys born to mothers with no living sons are more likely than girls to receive advice or treatment when sick with ARI (M/F odds ratio well above 1.00), and the $\mathrm{M} / \mathrm{F}$ odds ratio declines as mother's number of living sons increases. The only exception is births of order $4+$ to mothers with no living sons in NFHS-1 (OR $=0.81$; n.s.), which may be due to the very small number of cases in this category. The M/F odds ratios for treatment-seeking for ARI are especially large for second-order births to mothers with no living sons in both NFHS- 1 and NFHS-2 (OR=2.67; $p<0.01$ in NFHS-1 and $\mathrm{OR}=1.59 ; p<0.05$ in NFHS-2). Thus, in all but one case, the odds ratios indicate that, at any given birth order, discrimination against girls in treatment-seeking for ARI declines as mother's number of living sons increases.

The patterns of sex differentials in treatment-seeking for diarrhea are generally similar to those for ARI. In NFHS-1, the clearest evidence of gender discrimination in treatmentseeking for diarrhea is at birth order 3 . In this case births to mothers with no living sons are more than twice as likely to receive advice or treatment for diarrhea as girls 
$(\mathrm{OR}=2.19 ; p<0.01)$. The $\mathrm{M} / \mathrm{F}$ odds ratio declines to 1.47 in families with one living son and one living daughter, and further to 0.94 in families with two living sons. At birth orders 2 and $4+$ the pattern is less consistent in NFHS-1 but still strongly present in NFHS-2. In NFHS-2, the pattern of declining M/F odds ratios as mother's number of living sons increases is found at every birth order.

Nutritional status. In Table 2, we noted that there are no sex differentials in the prevalence of stunting, underweight, wasting, or anemia among children under age 3, except for more wasting among boys than among girls in NFHS-1. Table 3 shows that, when $\mathrm{M} / \mathrm{F}$ odds ratios for these measures are examined by child's birth order and mother's number of living sons, some evidence of gender discrimination emerges.

In the case of stunting at birth order 3 in each survey, M/F odds ratios tend to be well below 1.00 when the mother has no living sons, increasing to values well above 1.00 when the mother has two living sons. In NFHS-2, for example, M/F odds ratio increases from $0.64(p<0.01)$ when mother has no living sons to $1.54(p<0.1)$ when mother has two living sons. This indicates that boys are less likely than girls to be stunted when all older living siblings are girls (i.e., when boys are in short supply), and more likely than girls to be stunted when all older siblings are boys (i.e., when girls are in short supply). This pattern is also observed at birth order 4+ in NFHS-1, but not in NFHS-2. In her study of rural India based on NFHS-1, Pande (2003) also found a significant effect of oldersibling sex composition on stunting. 
In the case of underweight, the M/F odds ratios in NFHS-2 consistently indicate a systematic pattern of gender discrimination, inasmuch as odds ratios at a particular birth order tend to increase as the mother's number of living sons increases, especially at birth orders 2 and $4+$. This pattern is largely absent, however, in NFHS-1. In the case of wasting, M/F odds ratios increase as mother's number of living sons increases at birth order 2 in both surveys, but this pattern is absent at other birth orders. In the case of anemia in NFHS-2, it is largely absent at all birth orders.

\section{North and south compared}

There has been much discussion of north-south differences in gender roles and status of women in India. It is often argued that females enjoy a much more egalitarian status relative to men in the south than in the north, and that the extent of intra-household discrimination against girls is much less in the south than in the north. In this section we repeat the above multivariate analysis separately for four northern states (Bihar, Madhya Pradesh, Rajasthan, and Uttar Pradesh) and four southern states (Andhra Pradesh, Karnataka, Kerala, and Tamil Nadu). The four northern states are known to be less socioeconomically developed and to have higher fertility, higher infant and child mortality, stronger preference for sons, and lower status of women relative to men than the four southern states. Our purpose here is to test whether the extent of gender discrimination pertaining to nine of our outcome variables ${ }^{21}$ differs between the two groups of states. The analysis is carried out after pooling the data from NFHS-1 and

NFHS-2 in order to increase the number of cases. ${ }^{22}$ Results are presented in Table 4.

$$
<\text { Table } 4 \text { about here }>
$$


Childhood feeding. At birth order 3 there is evidence of sex differentials in feeding solid or mushy foods to children age 6-9 months. The effect of sex of index child is much stronger in the north than in the south, as indicated by a steeper increase in the north than in the south in the M/F odds ratio as mother's number of living sons increases. In the north, boys are much less likely than girls to receive solid or mushy foods in families with no living sons ( $\mathrm{OR}=0.37 ; p<0.05)$, but much more likely than girls to receive solid or mushy foods in families with two living sons $(\mathrm{OR}=5.22 ; p<0.1)$. A similar pattern of increasing odds ratios is also observed in the south, but it is less extreme, and the odds ratios are no longer statistically significant. The pattern is not observed in either north or south, however, at birth orders 2 and $4+$.

Among children age 24-35 months at birth orders 2 and 3, the M/F odds ratio for breastfeeding 24 months or longer rises as mother's number of living sons increases, contrary to expectation. At birth order 4+, however, this odds ratio declines as mother's number of living sons increases, consistent with expectation. Overall, there is no consistent pattern in either north or south, although the patterns are rather similar in both. The pattern at birth order $4+$ suggests that gender discrimination in breastfeeding is more common among higher-parity women, many of whom are having another child only in order to get a son (if they have no son) or a daughter (if they have no daughter).

In the north, the $\mathrm{M} / \mathrm{F}$ odds ratio for receiving milk daily falls as mother's number of living sons increases at birth order $4+$, but this pattern is not found in the south or at lower birth orders in either region. 
Immunization and health care. Table 4 also shows that boys are more likely to be fully immunized than girls in the north at most birth orders and sex compositions of older living siblings, providing clear evidence of widespread discrimination against girls in seeking preventive health care. This discrimination is particularly acute at birth orders 2 and 3 with no living sons $(\mathrm{OR}=1.74 ; p<0.01$ at birth order 2 with no living sons, and $\mathrm{OR}=2.49 ; p<0.01$ at birth order 3 with no living sons). There is no evidence of discrimination against girls in immunization coverage in the south, consistent with expectation.

Results for ARI treatment-seeking for births of order 3 whose mothers have no living sons and births of order 4+ whose mothers have no living sons are based on very small numbers of cases. For all other birth orders and sex compositions of older living siblings there is strong evidence of discrimination against girls in treatment-seeking for ARI in both north and south. For example, among second-order births in families with no living sons, boys are more than twice as likely as girls to receive advice or treatment when sick with ARI in both north and south ( $\mathrm{OR}=2.30 ; p<0.01$ and $\mathrm{OR}=2.30 ; p<0.05$, respectively). Even at birth order 1, boys are much more likely than girls to receive ARI treatment, and more so in the south than in the north. In both north and south, such discrimination against girls is not seen in families where all previous living children are sons $(2+$ sons in the case of birth order $4+$ ). 
Results for diarrhea treatment are more mixed. M/F odds ratios for treatment-seeking for diarrhea fall as mother's number of living sons increases at birth orders 3 and $4+$ in the south, but at other birth orders in the two regions the M/F odds ratios vary erratically. Overall, the evidence of gender discrimination in diarrhea treatment is stronger in the south than in the north but still rather weak in both regions.

Nutritional status. In the case of stunting, the clearest evidence of gender discrimination is at birth order 3 . In both north and south, the $\mathrm{M} / \mathrm{F}$ odds ratios are significantly less than 1.00 when there are no older male siblings $(\mathrm{OR}=0.69 ; p<0.05$ and $\mathrm{OR}=0.63 ; p<0.1$, respectively). The $\mathrm{M} / \mathrm{F}$ odds ratios increase as mother's number of living sons increases, indicating that girls tend to be more stunted than boys when boys are in short supply. The pattern is stronger in the south than in the north, contrary to expectation. A similar pattern of increasing $\mathrm{M} / \mathrm{F}$ odds ratios is also observed in the south at birth order $4+$, but not in the north.

In the case of underweight, $\mathrm{M} / \mathrm{F}$ odds ratios again tend to increase as mother's number of living sons increases. The pattern is seen at every birth order in the south and it is stronger in the south than in the north, contrary to expectation. In the case of wasting, the pattern of increase in M/F odds ratios as mother's number of living sons increases occurs only at birth order 2 in both regions. The pattern is otherwise inconsistent and erratic. 


\section{CONCLUSION}

The analysis indicates gender discrimination in childhood feeding, immunization coverage, treatment-seeking, and nutritional status in India. A consistent pattern is not observed across the board, however. The presence and extent of gender discrimination depend to a considerable extent on the birth order of the index child and the sex composition of older living siblings. Discrimination against girls is most visible in families with no living sons, particularly at birth orders 3 and $4+$. But not all gender discrimination in India is against girls. There is also evidence of discrimination against boys in families where older siblings are all boys.

In the case of childhood feeding, there is some evidence of discrimination against girls in feeding solid or mushy food at age 6-9 months at birth order 3, in breastfeeding 24 months or longer at birth order 4+, and in receiving other milk daily at birth order 4+. This evidence is stronger in NFHS-2 than in NFHS-1, and stronger in the north than in the south. Effects vary by birth order, however, so that overall the evidence is rather weak. There are no sex differentials in the proportion of children receiving green, leafy vegetables or fruits daily by child's birth order and mother's number of living sons. This may occur because green, leafy vegetables are not considered to be valuable foods, compared with milk, ghee (purified butter), or meat.

In the case of immunization coverage, the evidence of discrimination against girls is stronger in NFHS-2 than in NFHS-1. There is strong evidence of discrimination against girls in immunization coverage in the north, particularly in families with no living sons, 
but there is no evidence of such discrimination in the south. This may be partly due to much higher overall immunization coverage in the south than in the north. Evidence of gender discrimination is stronger in the case of treatment-seeking for ARI and diarrhea in both surveys and in both north and south. In the south, there is also some evidence of discrimination against boys in immunization and in treatment-seeking for ARI and diarrhea when girls are in short supply.

Regarding measures of nutritional status, there is clear evidence of gender discrimination for stunting and underweight, but not for wasting and anemia. The evidence is stronger in NFHS-2 than in NFHS-1 and stronger in the south than in the north. There is also some evidence of offsetting effects for stunting and underweight, where discrimination against girls when there are no living sons is cancelled out to some extent by discrimination against boys when there are no living daughters (again mainly in NFHS-2 and in the south), but no evidence of offsetting effects for wasting or anemia.

Our findings are consistent with previous studies in South Asia that show that excess female childhood mortality is greater in families with older female siblings (Das Gupta 1987; Muhuri and Prestion 1991, Arnold et al. 1998). However, our finding that for certain outcome variables discrimination against girls is as strong (or stronger) in the south as in the north contradicts previous research (Dyson and Moore 1983; Clark 2000). Our research goes beyond earlier studies in showing that some discrimination against girls in exclusive breastfeeding may benefit girls more than boys, and that there is some discrimination against boys in families with no living daughters. 
Our findings suggest three possible reasons for the lack of evidence of gender discrimination pertaining to children's nutritional status in more aggregated analyses (Marcoux 2002; Sommerfelt and Arnold 1998). First, discrimination against girls is not as widespread as argued by some and generally believed. It is limited to children of certain birth orders and sex compositions of older siblings, who constitute a relatively small fraction of all children, resulting in a small overall effect. Second, discrimination against girls when boys are in short supply and discrimination against boys when girls are in short supply cancel each other to some extent. Third, some discrimination against girls (for example, in exclusive breastfeeding at age 6-9 months) harms boys more than girls, again canceling out discrimination against girls to some extent.

\footnotetext{
${ }^{1}$ In this study, "gender discrimination" and "sex differential" are used interchangeably. It should be noted, however, that sex differences do not necessarily indicate conscious gender discrimination. Some discrimination or neglect may be unintentional. We do not distinguish between intentional and unintentional discrimination.

${ }^{2}$ Actually a date cut-off was used in place of an age cut-off. In NFHS-1, the cut-off for questions on births was January of the fourth calendar year before the survey, and in NFHS-2, it was January of the third calendar year before the survey. For any given woman, information was obtained for a maximum of three births during the four years before NFHS- 1 and for a maximum of two births during the three years before NFHS-2.

${ }^{3}$ Includes green, leafy vegetables and fruits as well as any other solid or mushy food. The question in NFHS-2 separately asked about "green, leafy vegetables", "fruits", and "any other solid or mushy food." The question in NFHS-1 only asked about "any solid or mushy food."

${ }^{4}$ Information on green, leafy vegetables and fruits was not collected in NFHS-1.

${ }^{5}$ Does not include breast milk or powdered milk. For NFHS-1, the information on milk pertains to the last 24 hours (yesterday or last night), whereas for NFHS-2 it pertains to daily (every day).

${ }^{6} \mathrm{~A}$ child is defined as fully immunized if it received BCG vaccine, three doses of DPT vaccine, three doses of polio vaccine (excluding Polio 0 ), and measles vaccine. The 12-35-month age range was selected because, according to health guidelines, children should be fully immunized by the time they complete their first year of life.
} 


\begin{abstract}
${ }^{7}$ ARI is defined as coughing accompanied by short, rapid breathing.
${ }^{8} \mathrm{~A}$ child is defined as stunted if child's height-for-age is more than two standard deviations below the median of an international reference population recommended by the World Health Organization (Dibley et al. 1987a; 1987b). Underweight (based on weight-for-age) and wasted (based on weight-for-height) are similarly defined. In NFHS-1, height was not measured in Andhra Pradesh, Himachal Pradesh, Madhya Pradesh, Tamil Nadu, and West Bengal. Children from these five states are excluded from the analysis of NFHS-1 data when these outcomes are analyzed.
\end{abstract}

${ }^{9}$ Childhood anemia is defined as a blood hemoglobin level of less than $11.0 \mathrm{~g} / \mathrm{dl}$. Data on anemia were not collected in NFHS-1.

${ }^{10}$ The body mass index (BMI) is defined as the ratio of weight in kilograms to the square of height in meters $\left(\mathrm{kg} / \mathrm{m}^{2}\right)$. Underweight is defined as a BMI of less than 18.5 , normal as a BMI of 18.5-24.99, and overweight or obese as a BMI of 25 or higher.

${ }^{11}$ Anemia in women is defined as a hemoglobin level of less than $11.0 \mathrm{~g} / \mathrm{dl}$ for pregnant women and less than $12.0 \mathrm{~g} / \mathrm{dl}$ for nonpregnant women.

12 "Primary school complete" means 5-7 completed years of education, "middle school complete" means 8-9 completed years of education, "high school complete" means 10 or more completed years of education.

${ }^{13}$ Other religions include Sikh, Christian, Buddhist, Jain, Jewish, Zorastrian, and others.

${ }^{14}$ In NFHS-1, the classification is: scheduled caste, scheduled tribe, other. Scheduled castes and scheduled tribes are castes and tribes that the Government of India identifies as socially and economically backward and in need of special protection from social injustice and exploitation.

${ }^{15}$ Standard of living is defined as an index based on ownership of a number of different consumer durables and other household items. The definition of the index varies slightly between NFHS-1 and NFHS- 2 .

In NFHS-1, standard of living is measured by an index defined in terms of ownership of household goods. The standard of living (SLI) index is calculated by adding the following scores: house type: 4 for pucca, 2 for semi-pucca, 0 for kachha; toilet facility: 4 for own flush toilet, 2 for public or shared flush toilet or own pit toilet, 1 for shared or public pit toilet, 0 for no facility; source of lighting: 2 for electricity, 1 for kerosene, gas or oil, 0 for other source of lighting; main fuel for cooking: 2 for electricity, liquified natural gas, or biogas, 1 for coal, charcoal, or kerosene, 0 for other fuel; source of drinking water: 2 for pipe, hand pump, or well in residence/yard/plot, 1 for public tap, hand pump, or well, 0 for other water source; separate room for cooking: 1 for yes, 0 for no; ownership of house: 2 for yes, 0 for no; ownership of agricultural land: 4 for 5 acres or more, 3 for 2.0-4.9 acres, 2 for less than 2 acres or acreage not known, 0 for no agricultural land; ownership of irrigated land: 2 if household owns at least some irrigated land, 0 for no irrigated land; ownership of livestock: 2 if own livestock, 0 if not own livestock; durable goods ownership: 4 for a car or tractor, 3 each for a scooter/motorcycle or refrigerator, 2.5 for a television, 2 each for a bicycle, electric fan, radio/transistor, sewing machine, water pump, bullock cart, or thresher, 1 for a clock/watch. Index scores range from 0-10 for low SLI to 10.5-20 for medium SLI and 20.5-45.5 for high SLI.

In NFHS-2, standard of living is measured by an index calculated by adding the following scores: house type: 4 for pucca, 2 for semi-pucca, 0 for kachha; toilet facility: 4 for own flush toilet, 2 for public or shared flush toilet or own pit toilet, 1 for shared or public pit toilet, 0 for no facility; source of lighting: 2 for electricity, 1 for kerosene, gas or oil, 0 for other source of lighting; main fuel for cooking: 2 for electricity, liquified natural gas, or biogas, 1 for coal, charcoal, or kerosene, 0 for other fuel; source of drinking water: 2 for pipe, hand pump, or well in residence/yard/plot, 1 for public tap, hand pump, or well, 0 for other water source; separate room for cooking: 1 for yes, 0 for no; ownership of house: 2 for yes, 0 for no; ownership of agricultural land: 4 for 5 acres or more, 3 for 2.0-4.9 acres, 2 for less than 2 acres or 
acreage not known, 0 for no agricultural land; ownership of irrigated land: 2 if household owns at least some irrigated land, 0 for no irrigated land; ownership of livestock: 2 if own livestock, 0 if not own livestock; durable goods ownership: 4 for a car or tractor, 3 each for a moped/scooter/motorcycle, telephone, refrigerator, or color television, 2 each for a bicycle, electric fan, radio/transistor, sewing machine, black and white television, water pump, bullock cart, or thresher, 1 each for a mattress, pressure cooker, chair, cot/bed, table, or clock/watch. Index scores range from 0-14 for low SLI to 15-24 for medium SLI to 25-67 for high SLI.

Because the SLI is calculated slightly differently in NFHS-1 and NFHS-2, comparisons of this index between the two surveys are not exact.

${ }^{16}$ North includes Delhi, Haryana, Himachal Pradesh, Jammu \& Kashmir, and Punjab. Central includes Madhya Pradesh, Uttar Pradesh, Bihar, and Rajasthan. East includes Orissa, and West Bengal. Northeast includes Arunachal Pradesh, Assam, Manipur, Meghalaya, Mizoram, Nagaland, and Sikkim. West includes Goa, Gujarat, and Maharashtra. South includes Andhra Pradesh, Karnataka, Kerala, and Tamil Nadu.

${ }^{17}$ Note that when comparing evidence of gender discrimination in northern and southern India, the four 'northern states' - Bihar, Madhya Pradesh, Rajasthan, and Uttar Pradesh — are different from those included in the 'north region'; whereas the four 'southern states'-Andhra Pradesh, Karnataka, Kerala, and Tamil Nadu - are the same as those included in the 'south region.'

${ }^{18}$ Apart from improvements in education, these changes may partly reflect differential fertility decline by mother's education.

${ }^{19}$ In NFHS-1, respondents were asked to report their caste or tribe status, and their answers were compared with the official government list of scheduled castes and scheduled tribes before re-coding the responses to scheduled caste, scheduled tribe, or "other". In NFHS-2, there was no checking against the official government list. Instead, respondents were first asked the name of their caste or tribe, if any. Then, if they belonged to a caste or tribe, they were asked whether they belonged to a scheduled caste, a scheduled tribe, an "other backward caste," or none of these. Because of these differences, the caste/tribe variable is not comparable between the two surveys.

${ }^{20}$ The form of the question was the same in both surveys: "At any time yesterday or last night, was (NAME) given any of the following:" The answer categories differed between the two surveys, however. In NFHS-1, the answer categories were plain water, sugar/honey water, juice, tea, baby formula, fresh milk, tinned/powdered milk, other liquids, any solid or mushy food. In NFHS-2, the answer categories were plain water, powdered milk, any other milk (other than breast milk), green leafy vegetables, fruits, any other solid or mushy food. Multiple answers were possible in both surveys.

${ }^{21}$ Two variables, receiving green, leafy vegetables or fruits daily and anemia, are excluded from this analysis, because NFHS-1 did not collect information on these variables.

${ }^{22}$ Even after pooling the samples, numbers of cases are small for certain variables and family-composition categories. This is especially so for the southern states in the analysis of feeding solid or mushy foods and in the case of ARI and diarrhea treatment for birth order 3, 0 sons and for birth order 4+, 0 sons. 


\section{REFERENCES}

Abeykoon, A.T.P.L. 1995. "Sex preference in South Asia: Sri Lanka an outlier," AsiaPacific Population Journal 10(3): 5-16.

Amin, S. 1990. "The effect of women's status on sex differentials in infant and child mortality in South Asia," Genus 46(3-4): 55-70.

Anandaiah, R. and M.K. Choe. 2000. Are the WHO Guidelines on Breastfeeding Appropriate for India? National Family Health Survey Subject Reports No. 16. Mumbai: International Institute for Population Sciences; and Honolulu: East-West Center.

Arnold, F. 1992. "Sex preference and its demographic and health implications," International Family Planning Perspective 18(3): 93-101.

Arnold, F. 2001. "Son preference in south Asia," Pp: 281-299 in Z.A. Sathar and J.F. Phillips (eds.), Fertility Transition in South Asia. Oxford: Oxford University Press.

Arnold, F., M.K. Choe, and T.K. Roy. 1998. "Son preference, the family-building process and child mortality in India," Population Studies 52: 301-315.

Arnold, F., S. Kishor, and T.K. Roy. 2002. "Sex-selective abortions in India," Population and Development Review 28(4): 1-28.

Bairagi, R. 1986. "Food crisis, nutrition, and female children in rural Bangladesh," Population and Development Review 12(2): 307-315.

Bairagi, R. and R.L. Langsten. 1986. "Preference for sex of children and its implications for fertility in rural Bangladesh," Studies in Family Planning 17(6): 302-307. 
Bardhan, P.K. 1988. "Sex disparity in child survival in rural India," in T.N. Srinivasan and P.K. Bardhan (eds.) Rural Poverty in South India. Oxford: Oxford University Press.

Basu, A.M. 1993. "How pervasive are sex differentials in childhood nutritional levels in south Asia?" Social Biology 40(1-2): 25-37.

Basu, A.M. 1989. "Is discrimination in food really necessary for explaining sex differentials in childhood mortalidy?" Population Studies 43(2): 193-210.

Behrman, J.R. 1998. "Intra-household allocation of resources: Is there a gender bias?" Pp: 223-242 in United Nations (ed.) Too Young to Die: Genes or Gender? New York: Department of Economic and Social Affairs, Population Division, United Nations.

Caldwell, P. and J.C. Caldwell. 1990. "Gender implications for survival in South Asia," Health Transition Working Paper No. 7. Canberra: National Centre for Epidemiology and Population Health, Australian National University.

Chen, L.C., E. Huq, and S. D’Souza. 1981. "Sex bias in the family allocation of food and health care in rural Bangladesh," Population and Development Review 7(1): 5570.

Choe, M.K., I. Diamond, F.A. Steele, and S.W. Kim. 1998. "Son preference, family building process and child mortality," Pp: 208-222 in United Nations (ed.) Too Young to Die: Genes or Gender? New York: Department of Economic and Social Affairs, Population Division, United Nations. 
Clark, S. 2000. "Son preference and sex composition of children: Evidence from India," Demography 37(1): 95-108.

D’Souza, S. and L.C. Chen. 1980. "Sex differentials in mortality in rural Bangladesh", Population and Development Review 6(2): 257-270.

Das, N. 1987. "Sex preference and fertility behavior: A study of recent Indian data," Demography 24(4): 517-530.

Das Gupta, M. 1987. "Selective discrimination against female children in rural Punjab, India," Population and Development Review 13(1): 77-100.

Das Gupta, M. and P.N. Mari Bhat. 1997. "Fertility decline and increased manifestation of sex bias in India," Population Studies 51(3): 307-315.

Dharmalingam, A. 1996. "The social context of family size preference and fertility behaviour in a South Indian village," Genus 52(1-2): 83-103.

Dibley, M.J., J.B. Goldsby, N.W. Staehling, and F.L. Trowbridge. 1987a. Development of normalized curves for the international growth reference: Historical and technical considerations. American Journal of Clinical Nutrition 46(5): 736-48.

Dibley, M.J., N.W. Staehling, P. Neiburg, and F.L. Trowbridge. 1987b. Interpretation of z-score anthropometric indicators derived from the international growth reference. American Journal of Clinical Nutrition 46(5): 749-62.

Dyson, T. and M. Moore. 1983. "On kinship structure, female autonomy, and demographic behavior in India," Population and Development Review 9(1): 3560. 
Elfindri. 1993. "Nutritional status of elementary school-age children in a rural population,” Majalah Demografi Indonesia (Indonesian Journal of Demography) 20(39): 31-49. [Abstract only]

Ganatra, B. and S. Hirve. 1994. "Male bias in health care utilization for under-fives in a rural community in western India," Bulletin of the World Health Organization 72(1): 101-104.

Gibson, R.S., E.L. Ferguson, and J. Lehrfeld. 1998. "Complementary foods for infant feeding in developing countries: Their nutrient adequacy and improvement," European Journal of Clinical Nutrition 52(10): 764-770.

Goodkind, D. 1996. “On substituting sex preference strategies in East Asia: Does parental sex selection reduce postnatal discrimination?" Population and Development Review 22(1): 111-125.

Gopalan, S. and R.K. Puri. 1992. "Breast feeding and infant growth," Indian Pediatrics 29(8): 1079-1086.

Govindaswamy, P. and B.M. Ramesh. 1997. Maternal Education and Utilization of Maternal and Child Health Services in India. National Family Health Survey Subject Reports No. 5. Mumbai: International Institute for Population Sciences; and Honolulu: East-West Center.

Haddad, L.J., C. Pena, C. Nishida, A. Quisumbing, and A. Slack. 1996. "Food security and nutrition implications of intrahousehold bias: A review of literature," FCND Discussion Paper No. 19. Washington, DC: International Food Policy Research Institute. 
Hill, K. and D.M. Upchurch. 1995. "Gender differences in child health: Evidence from the Demographic and Health Surveys," Population and Development Review 21(1): 127-151.

IIPS (International Institute for Population Sciences). 1995. National Family Health Survey (MCH and Family Planning): India 1992-93. Bombay: International Institute for Population Sciences.

IIPS (International Institute for Population Sciences) and ORC Macro. 2000. National Family Health Survey (NFHS-2), 1998-99: India. Mumbai: International Institute for Population Sciences.

Karki, Y.B. 1988. "Sex preference and the value of sons and daughters in Nepal," Studies in Family Planning 19(3): 169-178.

Kishor, S. 1993. "May god give sons to all: Gender and child mortality in India," American Sociological Review 58(2): 247-265.

Kishor, S. 1995. "Gender differentials in child mortality: A review of evidence," in M. Das Gupta, L.C. Chen, and T.N. Krishnan (eds.) Women's Health in India: Risk and Vulnerability. Bombay: Oxford University Press.

Koenig, M.A. and S. D’Souza. 1986. “Sex differences in childhood mortality in rural Bangladesh," Social Science Medicine 22(1): 15-22.

Levine, N.E. 1987. "Differential child care in three Tibetan communities: Beyond son preference," Population and Development Review 13(2): 281-304.

Makinson, C. 1994. "Discrimination against the female child," International Journal of Gynecology and Obstetrics 46(2): 119-125. 
Marcoux, A. 2002. "Sex differentials in undernutrition: A look at survey evidence," Population and Development Review 28(2): 275-284.

Miller, B.D. 1981. The Endangered Sex: Neglect of Female Children in Rural North India. Ithaca and London: Cornell University Press.

Mishra, V., S. Lahiri, and N.Y. Luther. 1999. Child Nutrition in India. National Family Health Survey Subject Reports No. 14. Mumbai: International Institute for Population Sciences; and Honolulu: East-West Center Program on Population.

Mishra, V. R.D. Retherford, and K.R. Smith. 2002. "Indoor air pollution: The quiet killer," Asia-Pacific Issues 63: 1-8.

Muhuri, P.K. and S.H. Preston. 1991. "Effects of family composition on mortality differentials by sex among children in Matlab, Bangladesh," Population and Development Review 17(3): 415-434.

Murthi, M., A. Guio, and J. Dreze. 1995. "Mortality, fertility and gender bias in India: A district-level analysis," Population and Development Review 21(4): 745-781.

Nag M. 1991. "Sex preference in Bangladesh, India and Pakistan, and its effect on fertility," Demography India 20(2): 163-185.

Niraula, B.B. and S.P. Morgan. 1995. "Son and daughter preferences in Benighat, Nepal: Implications for fertility transition," Social Biology 42(3-4): 256-273.

Pande, R. 2003. "Selective gender differences in childhood nutrition and immunization in rural India: the role of siblings," Demography 40(3): 395-418. 
Pebley, A.R. and S. Amin. 1991. "The impact of a public-health intervention on sex differentials in childhood mortality in rural Punjab, India," Health Transition Review 1(2): 143-169.

Pelletier, D. 1998. "Malnutrition, morbidity and child mortality in developing countries," Pp: 109-132 in United Nations (ed.) Too Young to Die: Genes or Gender? New York: Department of Economic and Social Affairs, Population Division, United Nations.

Ravindaran, T.K.S. and U.S. Mishra. 2000. "Health consequences of gender-based discrimination in childhood: A review of recent evidence," Paper presented at the WHO Meeting on Gender Analysis for Health, Geneva, 28-30, June.

Retherford, R.D. and T.K. Roy. 2003. Factor Affecting Sex-Selective Abortion in India and 17 Major States. National Family Health Survey Subject Reports No. 21. Mumbai: International Institute for Population Sciences; and Honolulu: East-West Center Program on Population.

Riley, N.E. 1997. “Gender, power, and population change," Population Bulletin 52(1): 48pp.

SAS Institute, Inc. 2001. The SAS System for Windows, Release 8.02. Cary, NC: SAS Institute, Inc.

Sen, A. and S. Sengupta. 1983. "Malnutrition of rural children and the sex bias," Economic and Political Weekly 18 (Annual Number, May): 855-864. 
Schoenbaum, M., T.H. Tulchinsky, and Y. Abed. 1995. "Gender differences in nutritional status and feeding patterns among infants in the Gaza Strip." American Journal of Public Health 85(7): 965-969.

Sommerfelt, A.E. and F. Arnold. 1998. "Sex differentials in nutritional status of young children," Pp: 133-53 in United Nations (ed.) Too Young to Die: Genes or Gender? New York: Department of Economic and Social Affairs, Population Division, United Nations.

Sommerfelt, A.E. and A.L. Piani. 1997. Childhood Immunization: 1990-1994. DHS Comparative Studies No. 22. Calverton, Maryland: Macro International Inc.

Sudha, S. and S.I. Rajan. 1999. "Female demographic disadvantage in India 1981-1991: Sex selective abortions and female infanticide," Development and Change 30(3): $585-618$.

Stash, S. 1996. "Ideal-family-size and sex-composition preferences among wives and husbands in Nepal," Studies in Family Planning 27(2): 107-118.

Stata Corporation. 2002. Stata Reference Manual, Release 8. College Station, TX: Stata Press.

Tabutin, D. and M. Willems. 1995. "Excess female child mortality in the developing world during the 1970s and 1980s," Population Bulletin of the United Nations 39: $45-78$.

Timaeus, I., K. Harris, and F. Fairbairn. 1998. “Can use of health care explain sex differentials in child mortality in the developing world," Pp: 154-178 in United 
Nations (ed.) Too Young to Die: Genes or Gender? New York: Department of Economic and Social Affairs, Population Division, United Nations.

Visaria, L. 1987. "Sex differentials in nutritional status in a rural area of Gujarat state: An interim report," Gujarat Institute of Area Planning Working Paper No. 7. Ahmedabad, India: Gujarat Institute of Area Planning.

Visaria, L. and P. Visaria. 1995. "India's population in transition," Population Bulletin 50(3): $1-51$.

WHO (World Health Organization). 2001. Global Strategy for Infant and Young Child Feeding. Document No. A54/INF.DOC/4. Geneva: World Health Organization. 
Table 1 Sample distribution of children under age 3 by birth order and sex composition of previous living children, and by selected background characteristics, India: NFHS-1 (1992-93) and NFHS-2 (1998-99)

\begin{tabular}{|c|c|c|c|}
\hline Characteristic & NFHS-1 & NFHS-2 & Both surveys \\
\hline \multicolumn{4}{|c|}{$\begin{array}{l}\text { Birth order, sex composition of living } \\
\text { sons, and sex of index child }\end{array}$} \\
\hline \multicolumn{4}{|c|}{ Birth order 1} \\
\hline $\mathrm{ICM}$ & 13.6 & 14.5 & 14.0 \\
\hline ICF & 12.9 & 13.1 & 13.0 \\
\hline \multicolumn{4}{|l|}{ Birth order 2} \\
\hline SOICM & 6.7 & 7.6 & 7.1 \\
\hline SOICF & 6.5 & 6.2 & 6.4 \\
\hline S1ICM & 5.5 & 6.3 & 5.8 \\
\hline S1ICF & 5.5 & 6.0 & 5.7 \\
\hline \multicolumn{4}{|l|}{ Birth order 3} \\
\hline SOICM & 3.0 & 3.3 & 3.1 \\
\hline SOICF & 2.8 & 2.8 & 2.8 \\
\hline S1ICM & 4.4 & 4.8 & 4.6 \\
\hline S1ICF & 4.4 & 4.2 & 4.3 \\
\hline S2ICM & 1.7 & 1.4 & 1.6 \\
\hline S2ICF & 1.7 & 1.6 & 1.6 \\
\hline \multicolumn{4}{|l|}{ Birth order 4+ } \\
\hline SOICM & 2.6 & 2.6 & 2.6 \\
\hline SOICF & 2.3 & 1.9 & 2.1 \\
\hline S1ICM & 5.8 & 5.5 & 5.7 \\
\hline S1ICF & 5.3 & 4.8 & 5.0 \\
\hline $\mathrm{S} 2+\mathrm{ICM}$ & 7.9 & 6.6 & 7.3 \\
\hline $\mathrm{S} 2+\mathrm{ICF}$ & 7.6 & 6.7 & 7.2 \\
\hline \multicolumn{4}{|l|}{ Child's age (months) } \\
\hline $0-5$ & 20.3 & 20.5 & 20.4 \\
\hline $6-12$ & 19.2 & 18.2 & 18.7 \\
\hline $12-23$ & 36.6 & 35.3 & 36.0 \\
\hline $24-35$ & 23.8 & 26.0 & 24.8 \\
\hline \multicolumn{4}{|l|}{ Previous birth interval } \\
\hline$<24$ months & 21.9 & 21.7 & 21.8 \\
\hline$>=24$ months & 78.1 & 78.3 & 78.2 \\
\hline \multicolumn{4}{|l|}{ Mother's age at birth (years) } \\
\hline$<20$ & 21.3 & 22.0 & 21.6 \\
\hline $20-34$ & 73.0 & 73.6 & 73.3 \\
\hline $35+$ & 5.7 & 4.4 & 5.1 \\
\hline \multicolumn{4}{|l|}{ Mother currently pregnant } \\
\hline Not pregnant & 89.7 & 90.2 & 90.0 \\
\hline First trimester & 2.5 & 2.8 & 2.6 \\
\hline Second trimester & 4.0 & 3.8 & 3.9 \\
\hline Third trimester & 3.7 & 3.2 & 3.5 \\
\hline \multicolumn{4}{|l|}{ Mother's BMI } \\
\hline Underweight & NA & 39.8 & NA \\
\hline Normal & NA & 55.6 & NA \\
\hline Overweight or obese & NA & 4.6 & NA \\
\hline \multicolumn{4}{|l|}{ Mother's anemia level } \\
\hline Normal & NA & 44.9 & NA \\
\hline Mild anemia & NA & 36.5 & NA \\
\hline Moderate or severe anemia & NA & 18.5 & NA \\
\hline \multicolumn{4}{|l|}{ Mother's education } \\
\hline Illiterate & 65.6 & 58.7 & 62.4 \\
\hline Literate, <middle complete & 16.6 & 17.7 & 17.1 \\
\hline Middle, <high school & 7.2 & 9.0 & 8.0 \\
\hline High school and above & 10.6 & 14.6 & 12.5 \\
\hline
\end{tabular}




\begin{tabular}{|c|c|c|c|}
\hline Urban & 22.7 & 22.2 & 22.4 \\
\hline Rural & 77.3 & 77.8 & 77.6 \\
\hline \multicolumn{4}{|l|}{ Religion } \\
\hline Hindu & 79.8 & 79.4 & 79.6 \\
\hline Muslim & 15.0 & 15.6 & 15.3 \\
\hline Other & 5.2 & 5.0 & 5.1 \\
\hline \multicolumn{4}{|l|}{ Caste/tribe } \\
\hline Scheduled caste & 13.2 & 20.0 & 16.4 \\
\hline Scheduled tribe & 9.4 & 9.6 & 9.5 \\
\hline Other backward caste & \# & 32.7 & \# \\
\hline Other & 77.4 & 37.7 & 74.1 \\
\hline \multicolumn{4}{|l|}{ Standard of living } \\
\hline Low & 41.5 & 37.1 & 39.4 \\
\hline Medium & 39.8 & 46.8 & 43.1 \\
\hline High & 18.7 & 16.1 & 17.5 \\
\hline \multicolumn{4}{|l|}{ Region } \\
\hline North & 6.6 & 6.2 & 6.4 \\
\hline West & 13.1 & 13.3 & 13.2 \\
\hline Central & 46.4 & 47.1 & 46.7 \\
\hline East & 11.0 & 10.8 & 10.9 \\
\hline Northeast & 4.2 & 3.3 & 3.7 \\
\hline South & 18.8 & 19.3 & 19.1 \\
\hline Number of children & & & \\
\hline
\end{tabular}

\# Combined with the "Other" category

Note: In the row headings for the composite variable, an entry such as SOICM means that mother's number of living sons $(\mathrm{S})$ is 0 and the gender of the index child (IC) is male. 
Table 2 Sex differentials in selected indicators of childhood feeding, health care, and nutritional status for four northern states, four southern states, and all India: NFHS-1(1992-93) and NFHS-2 (1998-99)

\begin{tabular}{|c|c|c|c|c|c|c|c|c|}
\hline \multirow[t]{2}{*}{ Characteristic } & \multicolumn{3}{|c|}{ NFHS-1 } & \multicolumn{3}{|c|}{ NFHS-2 } & \multicolumn{2}{|c|}{ Both surveys } \\
\hline & North & South & $\begin{array}{c}\text { All } \\
\text { India }\end{array}$ & North & South & $\begin{array}{c}\text { All } \\
\text { India }\end{array}$ & North South & $\begin{array}{r}\text { All } \\
\text { India }\end{array}$ \\
\hline
\end{tabular}

\section{Childhood feeding}

Received solid/mushy foods during the last 24 hours (age 6-9 months)

Boy
Girl
Boy
Girl

Receives green, leafy vegetables and fruits daily (age 12-35 months)
Boy

Receives milk daily (age 24-35)

Boy

Immunization and health care

Fully immunized (age 12-23 months)

Boy

Girl

Advice or treatment sought for ARI

Boy

Girl

Advice or treatment sought for diarrhea

Boy

Girl

\section{Nutritional status}

Stunted

Boy

Girl

Underweight

Boy

Girl

Wasted

Boy

Girl

Anemic

Boy

Girl

$\begin{array}{lll}18 & 54 & 32 \\ 23 & 55 & 34 \\ 79 & 59 & 72 \\ 75 & 52 & 68\end{array}$

NA NA NA

NA NA NA

$\begin{array}{lll}52 & 39 & 50\end{array}$

$\begin{array}{lll}53 & 38 \quad 48\end{array}$

$\begin{array}{lll}19 & 62 & 36 \\ 22 & 60 & 36 \\ 81 & 52 & 73 \\ 78 & 48 & 69\end{array}$

$\begin{array}{lll}18 & 58 \quad 34\end{array}$

$\begin{array}{lll}23 & 57 & 35\end{array}$

$80 \quad 55 \quad 73$

$77 \quad 50 \quad 68$

$\begin{array}{lll}22 & 54 & 36 \\ 16 & 52 & 34 \\ & & \\ 82 & 81 & 80 \\ 72 & 78 & 72 \\ & & \\ 73 & 70 & 70 \\ 66 & 64 & 65\end{array}$

$\begin{array}{lll}27 & 28 & 30\end{array}$

$\begin{array}{lll}27 & 29 & 29\end{array}$

NA NA NA

NA NA NA

$\begin{array}{lll}47 & 46 & 47\end{array}$

$\begin{array}{lll}49 & 44 & 48\end{array}$

$46 \quad 41 \quad 45$

$\begin{array}{llllll}42 & 42 & 43 & 46 & 41 & 45\end{array}$

NA: Not available

$\begin{array}{lllllllll}53 & 34 & 46 & 51 & 32 & 43 & 52 & 32 & 44 \\ 50 & 33 & 45 & 53 & 33 & 44 & 52 & 33 & 45 \\ & & & & & & & & \\ 59 & 43 & 52 & 50 & 35 & 44 & 55 & 39 & 48 \\ 55 & 46 & 51 & 53 & 37 & 47 & 54 & 41 & 49 \\ & & & & & & & & \\ 24 & 18 & 22 & 16 & 16 & 16 & 20 & 17 & 19 \\ 18 & 17 & 18 & 15 & 14 & 15 & 17 & 15 & 17 \\ & & & & & & & & \\ \text { NA } & \text { NA } & \text { NA } & 74 & 64 & 71 & \text { NA } & \text { NA } & \text { NA } \\ \text { NA } & \text { NA } & \text { NA } & 73 & 61 & 69 & \text { NA } & \text { NA } & \text { NA }\end{array}$


Table 3 Effects (M/F odds ratios) of sex of index child on selected indicators of childhood feeding, health care, and nutritional status by child's birth order and mother's number of living sons, India: NFHS-1(1992-93) and NFHS-2 (1998-99)

\begin{tabular}{|c|c|c|c|c|c|c|c|c|c|}
\hline \multirow[t]{2}{*}{ Characteristic } & \multirow[t]{2}{*}{ Birth order 1} & \multicolumn{2}{|c|}{ Birth order 2} & \multicolumn{3}{|c|}{ Birth order 3} & \multicolumn{3}{|c|}{ Birth order 4 and higher } \\
\hline & & 0 son & 1 son & 0 son & 1 son & 2 sons & 0 son & 1 son & $2+$ sons \\
\hline \multicolumn{10}{|c|}{ Childhood feeding } \\
\hline \multicolumn{10}{|c|}{$\begin{array}{l}\text { Received solid/mushy foods during the last } \\
24 \text { hours (age } 6-9 \text { months) }\end{array}$} \\
\hline NFHS-1 & 0.79 & 0.78 & 0.79 & 1.45 & 0.82 & 2.00 & 1.31 & 0.98 & 0.93 \\
\hline NFHS-2 & 1.07 & 1.07 & 1.03 & 0.81 & 1.24 & $5.53^{* *}$ & 0.55 & 0.99 & 0.81 \\
\hline Both surveys & 0.92 & 0.94 & 0.86 & 0.97 & 0.90 & 2.66 * & 0.90 & 1.04 & 0.91 \\
\hline \multicolumn{10}{|c|}{$\begin{array}{l}\text { Breastfed for } 24 \text { months or longer (age 24- } \\
35 \text { months) }\end{array}$} \\
\hline NFHS-1 & 0.99 & 1.00 & 1.16 & 1.03 & 1.40 & 1.96 * & 1.62 & 1.04 & 1.28 \\
\hline NFHS-2 & 0.99 & 1.31 & $1.61^{* *}$ & 1.11 & $1.72^{* *}$ & 1.17 & 1.78 & 1.14 & 0.80 \\
\hline Both surveys & 1.00 & 1.14 & 1.37 & 1.12 & 1.56 ** & 1.46 & 1.82 * & 1.15 & 1.00 \\
\hline \multicolumn{10}{|c|}{$\begin{array}{l}\text { Receives green, leafy vegetables and fruits } \\
\text { daily (age 12-35 months) }\end{array}$} \\
\hline NFHS-2 & 1.06 & 1.02 & 1.00 & 1.12 & 1.07 & 1.04 & 1.04 & 0.89 & 1.02 \\
\hline \multicolumn{10}{|c|}{ Receives milk daily (age 24-35) } \\
\hline NFHS-1 & 0.93 & 0.84 & 1.14 & 1.67 & 1.44 & 0.94 & 1.14 & 1.39 & 0.85 \\
\hline NFHS-2 & 1.14 & 1.27 & 1.11 & 0.97 & 0.87 & 1.05 & 1.46 & 1.06 & 1.06 \\
\hline \multicolumn{10}{|c|}{ Immunization and health care } \\
\hline \multicolumn{10}{|c|}{ Fully immunized (age 12-23 months) } \\
\hline NFHS-1 & 1.06 & 1.30 * & 1.12 & 1.08 & 1.28 & 0.98 & 1.16 & 1.58 ** & 1.01 \\
\hline NFHS-2 & 1.28 ** & 1.00 & 0.91 & $2.14^{* * *}$ & 1.31 & 0.74 & 1.17 & 1.22 & 0.95 \\
\hline Both surveys & 1.12 & 1.13 & 1.02 & $1.51 *$ & 1.25 & 0.84 & 1.19 & 1.39 * & 0.97 \\
\hline \multicolumn{10}{|c|}{ Advice or treatment sought for ARI } \\
\hline NFHS-1 & 1.47 & $2.67^{* * *}$ & 1.20 & 2.76 & $2.75^{* *}$ & 1.18 & 0.81 & $2.25^{* *}$ & 1.68 * \\
\hline NFHS-2 & 1.28 & $1.59 * *$ & 1.07 & 1.36 & 1.23 & 0.58 & 1.76 & $1.56 *$ & 1.18 \\
\hline Both surveys & 1.36 * & $1.71^{* *}$ & 1.15 & 1.67 & 1.50 & 0.79 & 1.57 & 1.61 * & 1.32 \\
\hline \multicolumn{10}{|c|}{ Advice or treatment sought for diarrhea } \\
\hline NFHS-1 & 1.17 & 0.77 & 1.12 & 2.19 ** & 1.47 & 0.94 & 0.59 & $1.87^{* *}$ & 1.48 * \\
\hline NFHS-2 & 1.11 & 1.64 ** & 1.15 & 1.55 & 1.35 & 1.12 & 1.41 & 1.15 & 0.78 \\
\hline Both surveys & 1.14 & 1.13 & 1.07 & 1.59 & 1.29 & 1.11 & 0.91 & 1.44 * & 1.03 \\
\hline \multicolumn{10}{|c|}{ Nutritional status } \\
\hline \multicolumn{10}{|l|}{ Stunted } \\
\hline NFHS-1 & 1.24 *** & 1.05 & 1.01 & 0.82 & 0.85 & 1.26 & 0.75 & 1.10 & $1.23^{* *}$ \\
\hline NFHS-2 & 0.96 & 0.98 & 1.04 & $0.64^{* * *}$ & 0.89 & 1.54 * & 1.04 & 0.86 & 0.91 \\
\hline Both surveys & 1.08 & 1.01 & 1.02 & $0.71 * *$ & 0.89 & 1.39 * & 0.90 & 0.96 & 1.10 \\
\hline
\end{tabular}




\begin{tabular}{|c|c|c|c|c|c|c|c|c|c|}
\hline \multicolumn{10}{|l|}{ Underweight } \\
\hline NFHS-1 & $1.13 *$ & 0.97 & 0.97 & 1.07 & 1.02 & 1.11 & 0.91 & 1.17 & 1.03 \\
\hline NFHS-2 & 0.98 & $0.79^{* *}$ & 1.02 & 0.83 & 0.83 & 1.08 & $0.63^{* *}$ & $0.77^{* *}$ & 0.94 \\
\hline Both surveys & 1.06 & 0.89 & 0.98 & 0.97 & 0.95 & 1.15 & $0.78^{*}$ & 0.97 & 1.01 \\
\hline \multicolumn{10}{|l|}{ Wasted } \\
\hline NFHS-1 & $1.34 * * *$ & 1.07 & 1.22 & $1.55^{* *}$ & 1.52 ** & $1.55^{*}$ & $1.60^{* *}$ & 1.06 & 1.22 \\
\hline NFHS-2 & 1.20 * & 1.10 & $1.38 * *$ & 0.89 & 1.11 & 0.98 & 0.83 & 0.99 & 0.99 \\
\hline Both surveys & $1.25^{* *}$ & 1.08 & $1.27^{*}$ & 1.18 & 1.31 * & 1.34 & 1.09 & 1.02 & 1.11 \\
\hline \multicolumn{10}{|l|}{ Anemic $^{a}$} \\
\hline NFHS-2 & 1.07 & $1.18^{*}$ & 1.20 * & 1.16 & 1.05 & 1.36 & 0.99 & 1.28 ** & 0.99 \\
\hline
\end{tabular}

$*<.1, * *<.05, * * *<.01$

${ }^{\text {a }}$ Not available for NFHS-1

NE: Not estimated due to insufficient numbers of cases in this category.

Note: Based on separate logistic regressions for each birth order within each survey. Explanatory variables include not only a composite variable for sex of index child and mother's number 
Table 4 Effects (M/F odds ratios) of sex of index child on selected indicators of childhood feeding, health care, and nutritional status by child's birth order and mother's number of living sons, four northern and four southern states of India: NFHS-1(1992-93) and NFHS-2 (1998-99) pooled sample

\begin{tabular}{|c|c|c|c|c|c|c|c|c|c|}
\hline \multirow[t]{2}{*}{ Characteristic } & \multirow[t]{2}{*}{ Birth order 1} & \multicolumn{2}{|c|}{ Birth order 2} & \multicolumn{3}{|c|}{ Birth order 3} & \multicolumn{3}{|c|}{ Birth order 4 and higher } \\
\hline & & 0 son & 1 son & 0 son & 1 son & 2 sons & 0 son & 1 son & $2+$ sons \\
\hline \multicolumn{10}{|c|}{ Childhood feeding } \\
\hline \multicolumn{10}{|c|}{$\begin{array}{l}\text { Received solid/mushy foods during the last } \\
24 \text { hours (age } 6-9 \text { months) }\end{array}$} \\
\hline North & 0.66 ** & 0.91 & 0.99 & $0.37^{* *}$ & 0.66 & 5.22 * & 0.42 & 1.26 & 0.75 \\
\hline South & 0.94 & 0.87 & 0.71 & 0.78 & 1.73 & 1.78 & 1.67 & 2.34 & 1.03 \\
\hline \multicolumn{10}{|c|}{$\begin{array}{l}\text { Breastfed for } 24 \text { months or longer (age 24- } \\
35 \text { months) }\end{array}$} \\
\hline North & 0.78 & 1.09 & 1.18 & 0.99 & 1.74 * & 1.54 & 1.82 & 1.21 & 0.94 \\
\hline South & 1.10 & 1.13 & $1.71^{* *}$ & 1.04 & 1.56 & 2.36 & $4.34^{* *}$ & 0.72 & 0.87 \\
\hline \multicolumn{10}{|c|}{ Receives milk daily (age 24-35) } \\
\hline North & 1.26 & 0.85 & 1.17 & 0.97 & 1.01 & 0.71 & $2.46 * * *$ & 1.43 * & 0.93 \\
\hline South & 0.93 & 1.19 & 0.78 & 0.83 & 2.68 * & $3.31^{* *}$ & 0.47 & 1.19 & 1.17 \\
\hline \multicolumn{10}{|c|}{ Immunization and health care } \\
\hline \multicolumn{10}{|c|}{ Fully immunized (age 12-23 months) } \\
\hline North & 1.39 ** & $1.74^{* * *}$ & 1.10 & $2.49 * * *$ & 1.25 & 1.56 & 1.32 & $1.82 * * *$ & 0.95 \\
\hline South & 1.01 & 1.05 & 0.93 & 0.73 & 1.22 & $0.45^{*}$ & 1.33 & 0.97 & 1.39 \\
\hline \multicolumn{10}{|c|}{ Advice or treatment sought for ARI } \\
\hline North & $1.38^{*}$ & $2.30^{* * *}$ & 1.28 & 1.56 & $2.37^{* * *}$ & 0.72 & 1.56 & $1.68^{* *}$ & 1.19 \\
\hline South & 2.64 ** & 2.30 ** & 0.51 & NE & 2.92 & 0.40 & 0.19 & 1.11 & 1.00 \\
\hline \multicolumn{10}{|c|}{ Advice or treatment sought for diarrhea } \\
\hline North & 1.40 * & 1.08 & 0.83 & 1.02 & 1.05 & 1.42 & 0.92 & 1.53 * & 0.94 \\
\hline South & 1.04 & 1.57 & $4.21 * * *$ & $6.98^{* * *}$ & 2.68 & 0.42 & 1.68 & 1.50 & 0.52 \\
\hline \multicolumn{10}{|c|}{ Nutritional status } \\
\hline \multicolumn{10}{|l|}{ Stunted } \\
\hline North & 1.07 & 1.02 & 1.16 & 0.69 ** & 0.86 & 1.01 & 1.06 & 0.99 & 1.14 \\
\hline South & 1.08 & 1.05 & 0.93 & $0.63 *$ & 0.91 & 1.72 & 0.61 & 0.79 & 1.08 \\
\hline \multicolumn{10}{|l|}{ Underweight } \\
\hline North & 1.10 & 1.01 & 1.07 & 1.26 & 1.04 & 1.29 & 0.77 & 1.17 & 1.01 \\
\hline South & 1.04 & 0.82 & 0.98 & 0.67 * & 0.81 & 1.07 & 0.55 * & 0.89 & 1.04 \\
\hline \multicolumn{10}{|l|}{ Wasted } \\
\hline North & 1.18 & 1.19 & 1.30 * & 1.92 *** & 1.37 & 1.73 * & 1.19 & 1.19 & 1.14 \\
\hline South & $1.47^{\text {** }}$ & 0.86 & 1.51 * & 0.94 & 1.01 & 0.87 & 1.32 & 0.77 & 0.82 \\
\hline
\end{tabular}

${ }^{*}<.1, \quad{ }^{* *}<.05, \quad{ }^{* * *}<.01$

NE: Not estimated due to insufficient numbers of cases in this category.

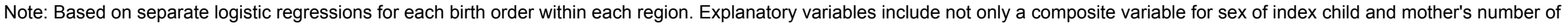
living sons but also the set of control variables included in Table 1. 